\title{
O Modernismo brasileiro e Montaigne: A Antropofagia de Oswald de Andrade ${ }^{1}$
}

Celso Martins Azar Filho

\section{RESUMO:}

Para mostrar a decisiva influência de Montaigne na criação da metáfora oswaldiana da Antropofagia como emblema da cultura brasileira, o presente artigo explica brevemente seu funcionamento teórico a partir de algumas de suas referências fundamentais.

Palavras-chave: Montaigne, Oswald de Andrade, Antropofagia, Modernismo

\section{ABSTRACT:}

Aiming to show how Montaigne's influence was decisive in the creation of oswaldian metaphor of Anthropophagy as Brazilian's culture emblem, this article explains briefly its theoretical functioning, examining some of its fundamental references.

Key-words: Montaigne, Oswald de Andrade, Antropophagy, Modernism

\footnotetext{
${ }^{1}$ Apresento aqui a versão em língua brasileira (e gostaria de agradecer a Sílvia Pimenta pelo auxílio na elaboração do presente texto) do artigo originalmente publicado no Bulletin de la Société des Amis de Montaigne, VII série, nº 19-20, juil-déc. 2000, p. 61-64.

${ }^{2}$ Celso Martins Azar Filho é Professor Adjunto na UFRRJ e Professor Permanente no Programa de Pós-Graduação em Filosofia do IFCS-UFRJ. Líder do Laboratório de Estudos Renascentistas (LERen) faz parte do núcleo de sustentação do GT Neoplatonismo da ANPOF. Tendo participado de grupos e atividades de pesquisa sobre o pensamento renascentista em diversos países, publicou vários artigos sobre o tema em periódicos nacionais e estrangeiros, além de um livro (A filosofia de Montaigne, 2009).
} 
O movimento literário e artístico brasileiro a que chamamos 'Modernismo', nascido em São Paulo em 1922, caracteriza-se por uma busca de temas extraídos da natureza e da cultura nacionais: é precisamente a definição de meu dicionário Larousse (verbete Modernisme). Nesse movimento, uma das imagens mais fortes e representativas, e que chegou mesmo a servir-lhe de bandeira, foi criada pelo escritor Oswald de Andrade. Ele convoca a antropofagia como metáfora para descrever o modo como o povo brasileiro se comporta diante da cultura, assim como o comportamento da própria cultura brasileira. A Antropofagia seria assim a verdade profunda do "ser cultural" brasileiro - o canibalismo como chave e emblema do caráter nacional. A ideia funcionou como um manifesto para os modernistas.

No entanto, poucas pessoas, tanto no Brasil como na França, conhecem suficientemente a influência decisiva exercida pelos Ensaios de Montaigne na criação dessa noção fundamental para os modernistas. Ora, nos textos mais importantes relacionados à Antropofagia, Oswald de Andrade se refere diretamente a este livro: desde o próprio Manifesto Antropófago, texto essencial e, de certo ponto de vista, inaugural ${ }^{3}$, até a Marcha das Utopias, bem posterior e que fornece uma das sínteses maiores da concepção filosófica de seu autor. Os escritos de Montaigne sobre os habitantes do Novo Mundo, e sobretudo o capítulo Des cannibales ( $31^{\circ}$ do primeiro livro dos Ensaios), inspiraram desse modo a literatura e a arte brasileira em um de seus momentos cruciais; e os ecos desse encontro ainda são percebidos de modo bem claro ${ }^{4}$.

No movimento modernista, o nacionalismo era fundamentalmente uma trincheira para lutar pela liberdade de criação e pela experimentação estética. Impunha-se uma ruptura com as tradições acadêmicas, que eram então frequentemente identificadas com tradições importadas. E o detalhe interessante é que, aqui, uma influência estrangeira tenha tido um peso significativo; e, paradoxalmente, que um dos elementos mais nacionalistas - o canibal, o autóctone da terra brasilis - seja, ao menos em parte, de origem francesa. No entanto, nenhuma incoerência nisto: vemos muito bem aí o funcionamento da atitude antropofágica tal como Oswald a define - a deglutição do estrangeiro.

A Antropofagia não é apenas um diagnóstico, é também e antes de tudo uma espécie de brasão, um símbolo armorial utilizado, ele próprio, como arma. Saborear Montaigne para assimilálo e transformá-lo numa perspectiva própria é apenas uma das possibilidades do ativismo

\footnotetext{
${ }^{3}$ Que chega a motivar uma revista - a Revista de Antropofagia ( $1^{\circ}$ número: maio de 1928$)$ - para servir de veículo às ideias do grupo dirigido por Oswald, o mais incisivo da fase polêmica do Modernismo.

${ }^{4}$ Por exemplo, a Bienal de São Paulo de 1998 teve a Antropofagia como tema.
} 
antropófago; que aliás, nesse caso particular, volta-se para alguém que é percebido como um aliado. Não é por acaso que, no Manifesto Antropófago, um parágrafo começando com a palavra 'Filiação' cita a seguir a frase montaigniana 'Où Villegaignon print terre', seguida do nome de seu autor (Andrade, 1990, vol. 6, p. 48). A Antropofagia é um primitivismo e sua visão da vida primitiva tem como fonte o ensaio Dos Canibais $^{5}$. Mas ela é também, e isso constitui um aporte significativo, um futurismo ${ }^{6}$ : por um lado, a valorização das origens e do primitivo não impede o interesse pelo progresso técnico (como vemos, por exemplo, na expressão "bárbaro tecnizado" ) ${ }^{7}$; por outro, o que remete ainda à sua relação com a filosofia montaigniana, a volta às raízes tem como objetivo uma convergência de forças para construir o futuro. O antropófago oswaldiano terá virtudes e qualidades muito semelhantes às do canibal dos Ensaios - a liberdade, a justiça, a alegria, a força, a coragem, a felicidade, etc - e são essas as virtudes que iriam engendrar e dar forma à cultura brasileira e pavimentar seu caminho em direção ao futuro.

Os modernistas fizeram do canibalismo dos primeiros brasileiros ao mesmo tempo um mito de origem e uma utopia: é preciso projetar a idade de ouro antropofágica no futuro para que o Brasil possa cumprir seu destino reencontrando a si mesmo. Essa intenção primordial serve a Oswald como guia para ler Montaigne: quando o primeiro concede a este uma posição preeminente entre os humanistas - o ensaísta, segundo o escritor brasileiro, exprimiu "o sentido de seu ciclo" - é porque ele foi capaz de determinar em um único ensaio (o Dos Canibais) "as linhas mestras da humanidade futura" (1990, vol. 21, p. 254-255). Mas essas palavras não remetem unicamente ao povo brasileiro. Há também considerações quanto ao efeito dessas ideias na cultura e na civilização do próprio velho mundo.

Segundo Oswald, o pensamento exposto no capítulo Dos Canibais deveria guiar não apenas o país dos canibais, mas também a Europa. E aqui, devemos lembrar que Montaigne já havia aconselhado seus contemporâneos a aproveitar a influência benéfica dos habitantes do Novo Mundo. Mas com a pretensão nacionalista que marca o movimento antropofágico, o modernista declara de modo provocador ter o Brasil, através dos Ensaios, influenciado de modo significativo acontecimentos capitais da história europeia. Para avaliar esta tese, devemos nos voltar para um livro de outro autor brasileiro: O Índio Brasileiro e a Revolução Francesa - As origens brasileiras da teoria da bondade natural, de Affonso Arinos de Mello Franco (MELLO FRANCO, 1937). Esta

\footnotetext{
${ }^{5}$ Ensaios I, 31. Cf. NUNES, 1990, p. 19: seja dito de passagem que a leitura deste texto de Benedito Nunes deve ser vivamente recomendada a todos os interessados no tema.

${ }^{6}$ E aqui é possível notar a presença das ideias da vanguarda europeia da época.
} 
obra, bem conhecida por Oswald de Andrade e mesmo citada por ele ${ }^{8}$, defende a tese de uma possível influência ideológica da imagem do índio brasileiro sobre a Revolução Francesa, através da noção de uma bondade da natureza, que uniria o humanismo da Renascença ao século das Luzes. Nesta hipótese, os Ensaios teriam sido uma referência central.

A tese de Arinos já foi contestada do ponto de vista historiográfico ${ }^{9}$ (e por outro lado seria difícil atribuir a Montaigne a ideia de uma bondade natural dos canibais), mas, para além de sua verdade ou falsidade, ela nos interessa pelo modo como Oswald e outros modernistas a utilizaram para fins políticos muito característicos. Uma das afirmações do Manifesto Antropófago (ANDRADE, 1990, vol. 6, p. 48) pode sintetizar esse propósito: “Sem nós a Europa não teria sequer a sua pobre declaração dos direitos do homem”. Isso significa que o encontro entre o novo e o velho mundo trouxe uma contribuição social e filosófica crucial para este último: na criação de valores humanistas que deveriam guiar a civilização europeia moderna, o contato com a cultura canibal foi determinante. E nesse episódio, como o escritor brasileiro não cansa de sublinhar, aqui como em outros textos, a obra de Montaigne teve um papel central. De acordo com ele, por exemplo, o desenvolvimento ideológico de que o ensaísta constituiria a origem conduz, por extensão, ao comunismo. E a afirmação dessa evolução histórica é também muito significativa para a Antropofagia: como o filósofo francês já havia notado, o comunismo era uma qualidade essencial da sociedade brasileira primitiva (ibidem, p.49). Assim, graças a Montaigne, o princípio igualitário desenvolvido pelos antropófagos chegará a influenciar inclusive a Revolução Bolchevique. Os Ensaios constituem "o grito inicial das revoluções de classe” (ANDRADE, 1990, vol. 21, p. 255), principalmente na famosa passagem em que seu autor dá a palavra aos próprios canibais (MONTAIGNE, 2004, 213-214). Notemos, além disso, que a liberdade - na simplicidade e no prazer de uma vida próxima à natureza - constitui outro valor muito importante na percepção montaigniana e oswaldiana do canibal. E frequentemente o modernista vai fazer o elogio da liberdade simultâneo ao do comunismo, ou seja, segundo seus objetivos políticos. Desse modo, os ideais que, graças à Revolução Francesa, vão mudar a face do mundo, teriam como origem os canibais brasileiros.

É porque vê bem suas implicações que o modernismo brasileiro quer romper de uma só vez com uma estética, uma moral e uma política reacionárias. Fala-se aqui da cultura brasileira como de

\footnotetext{
${ }^{7}$ ANDRADE 1990, vol. 6, p. 48. O interesse de Oswald pela tecnologia, a afirmação de seu papel no nivelamento das diferenças sociais, entra em geral em contradição com a visão montaigniana.

${ }^{8}$ O Achado de Vespúcio. In op. cit., vol. 6, p. 224-225. Notemos que aqui Oswald identifica a obra de Arinos como uma consequência da literatura "antropofágica" modernista de 1922.
} 
uma totalidade, de suas raízes até sua realização. Trata-se de reconhecer suas fontes e para elas retornar, reunindo forças para renovar suas possibilidades criativas originárias. Para alcançar esse fim, Oswald de Andrade, um dos mais importantes teóricos do movimento, teria tomado da obra de Montaigne uma parte essencial de suas ideias libertárias. Isso não significa que o modernista tenha seguido o pensamento dos Ensaios; ao contrário, ele se apropriou desse pensamento modificando o que era necessário para sua própria reflexão. Mas o aspecto essencial que a Antropofagia tirou de Montaigne e do qual se apropriou foi a lição de "Ver com os olhos livres" (ANDRADE, 1990, vol. 21, p. 44). Longe de fornecer uma chave ou um código para decifrar o universo ou a nós mesmos, o que o canibal montaigniano nos ensina é a manter o pensamento livre de preconceitos que impedem o conhecimento do outro e de si mesmo. Reencontrar a certeza instintiva, a virtude intuitiva, da alma primitiva do Brasil: é esta que deve, segundo os antropófagos modernistas, orientar a restauração de sua idade de ouro.

Renovação da vida, incorporação da divindade, vingança e celebração são algumas das noções que se integram ao "pensamento selvagem" do programa antropofágico, que até hoje deixa suas marcas no cenário cultural brasileiro. Reencontrar a mito-logia brasileira em uma filosofia mito-poética, assumida pela ingenuidade e pela ironia de uma lógica orgiástica do imaginário, é criar o anti-mito do antropófago. Desse modo, através de sua proto-história, o Brasil afirma sua própria identidade enquanto nação: a Antropofagia constitui uma espécie de gesta brasileira. $\mathrm{O}$ caráter negativo e devorador dessa imagem primordial, entretanto, deve sempre compreender em sua relação fundamental um aspecto positivo e produtivo, sem o qual se corre o risco, como ocorreu frequentemente e ocorre ainda, de privilegiar apenas aspectos que poderíamos chamar "digestivos" e transformadores, deixando de lado a qualidade de originalidade criadora que não se limita a uma pura cópia ou a uma pura imitação da civilização colonizadora, ainda que seja para revoltar-se contra ela. Deglutir a escravidão, as desigualdades e os tabus: tal é o mistério central do totem que devora a si mesmo. Assim é a floresta: alimentando-se de si mesma e permanentemente se engendrando sem cessar. No entanto, nada disso faz sentido se não percebemos suas possibilidades futuras, para além de uma simples contestação grotesca dos ideais e dos valores dos conquistadores - o que demonstraria ainda uma forma de dependência. Não se trata de opor nossas raízes e nossas origens a outras quaisquer - gregas, romanas ou tupis - mas justamente, como quis Montaigne, reencontrá-las em nós e nos reencontrarmos nelas.

Haveria ainda muito a dizer sobre o tema, embora este não seja o lugar: seria preciso desenvolvê-lo em contextos mais amplos para poder fornecer um panorama sublinhando a

\footnotetext{
${ }^{9}$ Dias (1973) assinala certos 'vícios de método' os quais, segundo suas conclusões, invalidariam a obra de Arinos.
} 
importância das ideias montaignianas para a cultura brasileira ${ }^{10}$. Aqui o objetivo é somente assinalar um dos momentos marcantes dessa influência. O ensaísta ficaria certamente muito surpreso se alguém lhe dissesse que um dia, no país dos canibais, suas palavras seriam retomadas para fundar a esperança de uma nova sociologia e uma nova filosofia. (ANDRADE, 1990, vol. 6, p. 201-202)

\footnotetext{
${ }^{10}$ Sobre o tema geral do Novo Mundo na obra montaigniana, publiquei desde então os seguintes textos: "Nouveau monde, homme nouveau". Montaigne Studies, vol. XXII, Chicago, 2010, p. 71-84; "Humanismo, antropologia e filosofia". In COSTA, A.; MORAES, F. de; MEDEIROS, N. de; HUSSAK, P. (Orgs.). Ética e Alteridade. Seropédica: EDUR, 2010 (CD-ROM); "The cannibal virtue". In NOIROT-MAGUIRE, C. e DIONNE, V. (Orgs.). Revelations of character - Ethos, rethoric and moral philosophy in Montaigne. Cambridge: Cambridge Scholars Publishing, 2007, p. 171-186 ; "Notes sur quelques thèmes communs aux Essais et à la pensée des Indiens brésiliens". Bulletin de la Société des Amis de Montaigne, Paris, vol. 33-34, 2004, p. 14-18; "Montaigne e o Brasil”. Paradigmas, Londrina, vol. III, n 2 , 2000, p. 95-101;
} 


\section{REFERÊNCIAS BIBLIOGRÁFICAS}

ANDRADE, O. Obras Completas de Oswald de Andrade. São Paulo: Ed. Globo / Secretaria de Estado da Cultura de São Paulo, 1990.

DIAS, J. S. da S. Os descobrimentos e a problemática cultural do século XVI. Coimbra: Universidade de Coimbra, 1973

MELLO FRANCO, A. A. de. O Índio Brasileiro e a Revolução Francesa - As origens brasileiras da teoria da bondade natural. Rio de Janeiro: José Olympio, 1937.

MONTAIGNE, M. de. Les Essais. Edição de Pierre Villey. Paris: PUF, 2004, p.213-214.

NUNES, B. "Antropofagia ao alcance de todos". In ANDRADE, O. ANDRADE, O. Obras Completas. São Paulo: Ed. Globo / Secretaria de Estado da Cultura de São Paulo, 1990.op. cit., vol. 6 , prefácio 